
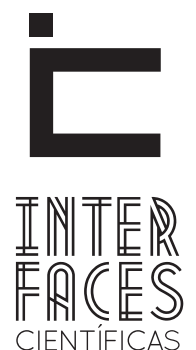

EDUCAÇÃO

ISSN IMPRESSO 2316-333X

ISSN ELETRÔNICO 2316-3828

DOI 10.17564/2316-3828.2015v4n1p47-56

\title{
A COMPANHIA DE JESUS: MODELO INOVADOR E MODERNIZANTE DO ENSINO NO INICIO DOS TEMPOS MODERNOS
}

Peter Johann Mainka ${ }^{1}$

\section{RESUMO}

Por volta de 1500, na virada da Idade Média para os Tempos Modernos, Estado e sociedade na Europa em geral e no Sacro Império Romano-Germânico passaram por transformações diferentes e profundas. Nesse período histórico de continuidade e mudança, de tensões e contradições, de tradição e inovação, a Companhia de Jesus, recém-fundada, se tornou um modelo inovador e modernizante da igreja católica, de Estado e sociedadee, especialmente, do ensino médio e superior. No foco deste artigo, colocaremos o momento histórico de reviravolta e a Companhia de Jesus que, como representante exemplar de um novo modelo de inovação e modernização, tornou-se o instrumento principal da Renovação Católica e da Contrarreforma no início dos Tempos Modernos, adquirindo monopólio no ensino médio e superior católico do Sacro Império Romano-Germânico, de quase toda Europa e, também, no Ultramar.

\section{PALAVRAS-CHAVE}

Companhia de Jesus. Tempos Modernos. Educação Católica. Ensino Médio e Superior. 


\section{ABSTRACT}

Around 1500, at the turning of the Middle Ages towards the modern times, state and society in Europe in general and in the Holy Roman Empire of the German Nation passed through different and profound transformations. In this historical period of continuity and change, of tensions and contradictions, of tradition and innovation, the Society of Jesus, recently founded, turned into a innovative and modernizing model of the Catholic Church, the state and the society, and, especially, of the secondary and tertiary education. The focus of this article is put on the historic about-face, when the Society of Jesus as prestigious example of a new model of innovation and moderni- sation turned into a main instrument of the Catholic Renewal and the Counter-Reformation at the beginning of the modern times, acquiring a monopoly at the secondary and tertiary catholic education in the Holy Roman Empire of the German Nation, in Europe and also nearly overseas.

\section{KEYWORDS}

Society of Jesus. Modern Times. Catholic Education. Secondary and Tertiary Education.

\section{RESUMÉN}

Alrededor de 1500, en el cambio de la Edad Media a los Tiempos Modernos, el Estado y sociedad tanto en Europa en general como en el Sacro Imperio Romano Germánico pasaron por transformaciones diferentes y profundas. En ese período histórico de continuidad y cambio, de tensiones y contradicciones, de tradición e innovación, la Compañía de Jesús, recién fundada, se volvió un modelo innovador y modernizador de la Iglesia Católica, de Estado y sociedad, y, especialmente, del Enseño medio y superior. En elfoco de este artículo colocaremos el momento histórico de cambio, la Compañía de Jesús como representante ejemplar de un nuevo modelo de innovación y modernización se volvió el instrumento principal de la Renovación Católica y de la Contrarreforma al comienzo de los Tiempos Modernos, adquiriendo un monopolio en el Enseño medio y superior católico del Sacro Imperio Romano Germánico, de Europa y casi también de Ultramar.

\section{PALABRAS CLAVE}

Compañía de Jesús. Tiempos Modernos. Educación Católica. Enseño Medio y superior. 


\section{A COMPANHIA DE JESUS: ORDEM DE MODERNIZAÇ̃̃O}

A história da Companhia de Jesus caracteriza, de modo especial e exemplar, a época dos Tempos Modernos. A militância e a firmeza eclesiástica e intelectual dessa ordem religiosa, fundada em 1534 por Inácio de Loyola (1491-1556) e reconhecida, oficialmente, em 1540 pelo papa Paulo III (1468-1549, papa desde 1534), refletem, evidentemente, os tempos agitados do seu nascimento. No decorrer das mudanças religiosas provocadas pela Reforma Protestante, pela Renovação Católica e pela Contrarreforma e em virtude da formação das confissões e dos processos múltiplos de "confessionalização", a igreja católica, no centro das críticas e pressionada, numa posição de defesa, teria de, sobretudo, certificar-se de si mesma e tentar realizar reformas necessárias quanto à estrutura e à doutrina, adaptando-se às condições gerais de mudanças no que diz respeito à politica, à sociedade e à economia.

Nesse momento histórico, era imprescindível aperfeiçoar o seu próprio perfil, assim como estabelecer fundamentos sólidos quanto à doutrina e quanto à organização em direção ao futuro, a fim de poder manter-se, de modo firme e autoconsciente, entre as igrejas e confissões nascentes.

Nesse período de transição da Idade Média para os Tempos Modernos, o mundo antigo tradicional sofreu, também, transformações profundas em muitas outras áreas da vida humana como em relação a Estado e sociedade, economia e cultura, pensamento e ciência, além das mudanças referentes à religião e à religiosidade, as quais resultaram na ruptura da unidade da cristandade ocidental.

A expansão europeia faz parte dessas transformações notáveis e modernizantes. A partir daí, o mundo antigo, ultrapassando os seus limites tradicionais, sejam geográficos ou culturais, começou a descobrir novos mundos e a conectar-se com eles, resultando, finalmente, num mundo globalizado e entrelaçado, de modo múltiplo. A Companhia de Jesus participava, de modo privilegiado desde a sua fundação, desse processo de globalização crescente e enlace múltiplo, atuando em todos os cantos do mundo conhecido e conseguindo, assim, a promoção do co-crescimento da humanidade.

Apesar das fortes críticas feitas ao longo dos Tempos Modernos e crescentes, especialmente, no século XVIII, ou seja, no século do Esclarecimento, as quais denunciaram os jesuítas como representantes do passado, conservadores, reacionários e inimigos de qualquer progresso, a Companhia de Jesus pode ser considerada, com todo direito, como a ordem que contribuiu muito e, no lado católico, decisivamente para o processo de modernização do mundo. A Societas Jesu foi constituída como organização racional, lógica e efetiva com uma hierarquia claramente estruturada, possibilitando, naquela época, um alto grau de eficiência e capacidade de atuar e de decidir num ambiente sempre mais complicado e diante de desafios crescentes.

Além dessa estrutura moderna, a Companhia de Jesus dispôs de fundamentos teóricos, espirituais e doutrinais que foram sistemáticos e lógicos, em todas os aspectos. Essa fundamentação racional da ordem se refletiu, também, no sistema claramente definido de escrever cartas e relatórios de baixo para cima, até a chefia da ordem, e possibilitou a sua atuação firme e decidida nos negócios do mundo. Essa atuação também se orientou, quando se fez necessário, nas necessidades do poder da 'razão do Estado', uma máxima política relacionada, de modo inseparavel, ao nome de Nicolau Maquiavel (14691527), que havia articulado, no seu Príncipe, normas rígidas para qualquer Estado forte.

Essa racionalidade, que caracterizava, em princípio, toda a Companhia de Jesus, foi responsável, de certa maneira, pela sua proximidade com os governantes e poderosos. Foram, por um lado, os próprios jesuítas que procuraram as relações com os reis e 
príncipes e, por outro lado, os soberanos e regentes que se aproximaram dos jesuítas e recorreram aos seus serviços como conselheiros e confessores.

A propagação da fé católica por catequese, sermão e missionarização foi o objetivo principal da Companhia de Jesus, a qual se tornou o instrumento mais eficaz da igreja católica reformada e consolidada pelo Concílio de Trento (1545-1563) que elaborou os novos alicerces dogmáticos do catolicismo moderno.

A ordem de Inácio de Loyola atuou em diferentes setores e níveis para fortalecer a igreja católica:

1. Nas regiões onde o catolicismo foi consolidado, dando assistência religiosa e pastoral, pregando nas paróquias e ensinando o verbo de Deus ao povo simples.

2. Nos territórios do Sacro Império Romano-Germânico e da Europa, onde existia uma parcela mais ou menos considerável de protestantes, combatendo os partidários de Martinho Lutero (1483-1546), da sua doutrina ou das outras correntes protestantes, e procurando recuperar os renegados por catequese e sermões ou por astúcia e rigidez.

3. Nas regiões recém-descobertas do mundo durante o processo de expansão europeia, missionarizando, catequisando e pregando o Evangelho aos gentios e pagãos considerados homens sem fé, lei e religião.

4. Contra os judeus e muçulmanos, considerados inimigos hereditários da cristandade, polemizando e agitando de modo parcial e fanático.

Os jesuítas, como teólogos, confessores e líderes espirituais, procuraram a proximidade das autoridades seculares e eclesiásticas e exerceram grande influência sobre a política dos príncipes e monarcas católicos, dos bispos e arcebispos; como professores, docentes e instrutores, dando aulas nas escolas e universidades, nos ginásios, liceus e colégios, conduziram a juventude à igreja católica e, finalmente, como pesquisadores, intelectuais e eruditos, dedicando-se às ciências humanas e naturais, contribuíram para a compreensão e o esclarecimento do mundo e do homem.

Apesar dos rigorosas critérios de recepção, o número dos membros aumentou, rapidamente. Em 1556, no ano da morte de Inácio de Loyola, aderiram por volta de 1500 membros à ordem em 12 províncias estabelecidas: quatro províncias na península ibérica (Portugal, Castela, Andalus/Bética e Aragón), cinco províncias no resto da Europa (Itália, Sicília, França, Baixa Alemanha/Países Baixos e Alta Alemanha) e três próvíncias no Ultramar (Î́ndia, Brasil e Etiópia).

O número dos membros continuou crescendo: em 1565, houve por volta de 3500 membros em 18 províncias; em 1580, mais que 6000 membros; em 1615, por volta de 13.000 membros; em 1680, por volta de 18.000 membros e, em 1750, 22.589 membros em 39 províncias. Cerca de $40 \%$ desses membros pertenceram às dez províncias unidas na Assistência Alemã (Baixa Renânia, Alta Renânia, Alta Alemanha, Boêmia, Áustria, Flandro-Belga, Gallo-Belga, Anglo-Irlanda, Polónia e Lituânia).

Quanto ao número, à Assistência Alemã seguiu as Assistências Espanhola, Francesa e Italiana - mais ou menos do mesmo tamanho - e a Assistência Portuguesa, com 1760 membros, era a mais pequena. Treze províncias, ou seja, um terço das 39 províncias existentes em meados do século XVIII, foram localizadas no Ultramar: cinco províncias na Ásia - Goa (estabelecida em 1549), Filipinas (1605), Malabar (1605), Japão (1611) e China (1623) - e oito províncias na América - Brasil (estabelecida em 1553), Peru (1568), México (1572), Paraguai (1604), Novo Granada (1609), Chile (1683), Quito (1696) e Maranhão (1725).

As províncias na Ásia pertenceram, com exceção da província das Filipinas, à Assistência Portuguesa; as províncias na América pertenceram - com exceção das províncias do Brasil e do Maranhão - à Assistência 
Espanhola. Além dessas províncias autónomas, houve Missões dependentes da Assistência Francesa nas Antilhas, em Québec, no Oriente Próximo e no Indo-China e, da Assistência Portuguesa, na África.

Segundo Pedro Borges Morán, 3189 jesuítas foram, nos Tempos Modernos, para a América Espanhola e as Filipinas, sendo 2340 espanhóis e 849 de outra nacionalidade ${ }^{2}$. A Companhia de Jesus representou 21,12\% de todos os missionários enviados da Espanha para as províncias ultramarinas. 0 historiador norte-americano Dauril Alden contou, ao todo, 2958 jesuítas - 2242 portugueses e 716 de outra nacionalidade -, que foram enviados de Portugal às províncias ultramarinas da Assistência Portuguesa (MEIER, 2007, p. 8).

A Companhia de Jesus foi caracterizada, como a maioria das ordens mendicantes, pelos ideais de pobreza, castidade e, além disso, por uma estrutura rigorosamente hierárquica. A direção da ordem competia a um general como superior, eleito pela vida inteira. $A$ Companhia se destacou pelo voto de obediência absoluta ao papa e pela renúncia a um hábito especial, a horários regulares de devotos conjuntos e ao convívio dos religiosos em mosteiros e conventos

\section{A COMPANHIA DE JESUS E A EDUCAÇÃO}

Inicialmente, a nova ordem acentuou a sua mobilidade, resultado da sua renúncia a se fixar num lugar de modo estável, atribuindo aos padres a liberdade e flexibilidade de atuar, espiritualmente, sem limites de espaço e em diferentes contextos. Por outro lado, a Companhia de Jesus reconheceu a importância da educação, que exigia uma certa estabilidade, e se dedicou logo à instrução de crianças e jovens. Quando houve um número suficiente de jesuítas, eles fundaram casas, residências e colégios, "que foram ligados, em princípio, com um ginásio, um liceu (institu-

2. No século XVI 332 espanhois e 19 de outra nacionalidade, no século XVII 943 espanhóis e 205 de outra nacionalidade e no século XVIII 1965 espanhóis e 625 de outra nacionalidade (MEIER, 2007, p. 8). ição de ensino filosofico/teológico) ou também com uma universidade" (MÜLLER, 1990, p. 55).

A partir de 1551, os jesuítas inauguraram, em média, quatro ou cinco escolas por ano (HAUB, 2007). Devido ao fato de que as suas escolas não foram restritas à nova geração de religiosos, mas logo se abriram para leigos, sem cobrar mensalidades, a procura de pais interessados numa educação qualificada cresceu.

Cada colégio foi ligado, geralmente, com uma instituição de ensino. Um estabelecimento jesuítico consistiu, geralmente, das seguintes construções: o prédio do colégio, uma igreja, um ginásio, liceu ou uma universidade e, às vezes, um seminário. A formação escolar dos jesuítas, tanto nos ginásios como nas universidades se orientou no sistema dos collegesusado nas universidades de Paris e Oxford, no modelo da universidade humanística em Louvain (Leuven) e também em elementos das universidades espanholas estabelecidas pelo Estado (MÜLLER, 1990, p. 55).

A maioria dos alunos morava em casa, embora os jesuítas preferissem a sua hospedagem num internato. 0 alojamento coletivo dos alunos numa instituição dos jesuítas garantia uma fiscalização dos alunos mais rígida e contribuía, nos tempos acirrados de lutas religiosas, para formar "um catolicismo relativamente homogêneo” (HAMMERSTEIN, 2003, p. 40).

Nos territórios católicos, o modelo da educação jesuítica se propagou rapidamente, conseguiu se impor e alcançou uma posição de monopólio em detrimento das escolas latinas ou dos ginásios municipais existentes. A qualidade do ensino jesuítico foi reconhecida, também, pelos protestantes e pelos adversários da ordem. O corpo docente, nas escolas e universidades da Companhia, foi bem qualificado em regra geral e em comparação com a média contemporânea.

O modelo exemplar da educação em geral e do ensino superior da Companhia de Jesus foi o Collegium Romanum, fundado em 1551 na cidade de Roma e diri- 
gida à educação das futuras elites da ordem e da igreja católica. O Collegium Romanum foi o terceiro colégio jesuítico na Itália - depois dos Colégios de Messina (fundado em 1548) e de Palermo (1549) - tornando-se o mais importante e influente da Companhia de Jesus.

Em 1552, o Papa Júlio III (1487-1555, papa desde 1550) elevou-o à categoria de universidade. Nessa universidade exemplar atuaram os melhores professores e eruditos e estudaram os futuros líderes e dirigentes da própria Societas Jesu e da igreja católica. 0 arquiteto inaciano Giuseppe Valeriani (1526-1596) construiu, entre 1583 e 1585, em nome do papa Gregório XIII (15021585, papa desde 1572), o complexo enorme do colégio na Piazza del Collegio Romano, em que funciona ainda hoje a assim chamada Universidade Gregoriana.

O ensino dos jesuítas seguiu um currículo uniforme que definiu os conteúdos, as disciplinas e os métodos didáticos: a Ratio atque institutio studiorum. As primeiras deliberações para esse regulamento de estudos haviam iniciado, ainda, nos tempos do fundador Inácio de Loyola. Em seguida, regras de ensino, feitas ad hoc para os colégios na Itália, França, em Portugal e na Alemanha, foram colecionadas e reunidas sob a direção do general Claudio Aquaviva (1543-1615, general desde 1581). Iniciou-se a uniformização dos regulamentos pedagógicos isolados, porém a redação última e definitiva demorou e data somente do ano de 1599, quando a Ratio entrou em vigor no dia 8 de janeiro.

A Ratio estabeleceu e garantiu um sistema escolar e educativo uniforme e válido em todos os estabelecimentos jesuíticos na Europa e no mundo inteiro, antecipando assim, de certa forma, o processo de Bolonha no âmbito europeu. A Ratio atque institutio studiorum "apresenta”, como escreve Rita Haub (2007, p. 44), "o currículo e os métodos de ensino em forma de uma coleção de regras práticas para os dirigentes das universidades, dos liceus e dos ginásios e para os seus órgãos executivos". Apesar de toda a uniformidade que garantiu a Ratio studiorum, as instituições jesuíticas da educação apresentaram, como novas pesquisas comprovam, diferenças notáveis quanto à estrutura e ao posiçionamento intelectual.

O sistema de ensino realizado pelos jesuítas foi caracterizado pela organização de turmas de escola sob a direção exclusiva de um professor, que deveria estabelecer relações pessoais com os alunos, pois confiança e amizade entre eles foram vistos como imprescindíveis para o sucesso de aprendizagem e ensino. Além disso, o ensinamento gradual e gradativo foi considerado fundamental, subindo pouco a pouco de um nível inferior a um mais elevado, sempre prestando atenção a que os alunos compreendessem, plenamente, os textos lidos e as matérias dadas: a esse objetivo serviram, sobretudo, os instrumentos didáticos de exercício, repetição e prática (HAUB, 2007, p. 44).

A Ratio studiorum estruturava o curso em três partes: 1. a filologia (latina) do ginásio (studia inferiora); 2. os estudos superiores (studia superiores), a saber, a filosofia no liceu ou na universidade e 3. a teologia na universidade - filosofia e teologia embasadas nos livros de Aristóteles (384-322 a.C.) e Tomás de Aquino (1225-1274) (HENGST, 1981, p. 55-79; HAMMERSTEIN, 2003, p. 38).

Nos liceus foram ensinadas as assim chamadas artes liberales do trívio (gramática, retórica e dialética) e do quadrívio (aritmética, geometria, astronomia e música). Essas disciplinas foram oferecidas, também, nas universidades, a saber, na faculdade mais ínfima, na faculdade artística, que os jesuítas aspiraram, de modo calculado, a conquistar (HARTMANN, 2008, p. 72). Liceus e universidades se diferenciavam pelo fato de que os liceus não possuíram privilégios universitários, outorgados pelo imperador ou pelo papa, e o direito de doutoramento. Somente a permissão do papa Pio IV (1499-1565, papa desde 1559) possibilitou a Companhia de Jesus a fundar universidades. 


\section{COLÉGIOS E GINÁSIOS JESUITTICOS}

Os colégios dos jesuítas se espalharam em todo o Sacro Império Romano-Germânico, especialmente na parte meridional e majoritariamente católica. Embora a nova ordem considerasse a mobilidade dos seus membros importante, os jesuítas começaram mais e mais lançar raízes locais, mantendo, no entanto, a conexão e comunicação internacional em âmbito global (FRIEDRICH 2011).

Foram fundados muitos colégios jesuíticos na segunda metade do século XVI, a maioria deles ligados com uma instituição escolar. Novos colégios nasceram, entre outros, em Viena (1552), Graz na Áustria e no território germânico em Colônia (Köln) [1543/44], Dillingen (1549), Ingolstadt (1556), München (1559), Tréveris (Trier) [1560], Mogúncia (Mainz) [1560/61], Würzburg (1567), Espira (Speyer) [1567/71], Fulda (1571), Paderborn (1580), Augsburg (1582), Münster (1588), Regensburg (1588) e Hildesheim (1595). Esses colégios se tornaram núcleos e centros da educação e do ensino da renovação católica e, sobretudo, da Contrarreforma. Além disso, os jesuítas aspiraram a elevar cursos existentes de filosofia e teologia para o nível de liceus ou a assumir a responsabilidade exclusiva sobre as faculdades de filosofia e teologia das universidades que já funcionavam.

Os fundamentos financeiros dos estabelecimentos jesuíticos, quanto às custas de construção e sustento foram, geralmente, sólidos e firmes: a pedido dos jesuítas, casas e prédios foram pagos ou cedidos à ordem, frequentemente, por terceiros, seja por autoridades seculares ou eclesiásticas (príncipes, municípios, bispos), seja por pessoas privadas que doaram à Companhia, também, quantias consideráveis de dinheiro. Os juros desse capital, aumentado, às vezes, por pagamentos adicionais, contribuíram para financiar as instalações físicas da Companhia, ou seja, casas e colégios, escolas e universidades.
O colégio jesuítico de Passau - capital de um Arcebispado na fronteira entre a Baviera e a Áustria, em que viviam, no século XVII, entre 4000 e 6000 habitantes - foi fundado no ano de 1611 a pedido do bispo Leopold de Áustria (1586-1632, bispo de 16051626). Leopold, da dinastia dos Habsburgos, doou, ao colégio, mais de 350.000 (352.940) florins, uma soma maior do que o rendimento anual do bispado. (HARTMANN, 2008, p. 69).

Outros colégios jesuíticos se acresceram, noséculo XVII, à rede existente, entre eles os colégios em Aachen (1601), Worms (1608), Bamberg (1611), Passau (1611), Eichstätt (1614), Erfurt (1611/15), Düsseldorf (1619), Breslau(1638) e em Linz (1600/1608) na Áustria. (KRAMMER, 1988), havendo, na Europa Central em meados do século XVII (1648), por volta de 70 colégios jesuíticos (HARTMANN, 2008, p. 68). A Companhia de Jesus dominou mais que $90 \%$ do ensino médio e superior nos territórios católicos do Sacro Império Romano-Germânico. Somente poucas outras ordens religiosas como, por exemplo, os beneditinos, conseguiram manter-sena área da educação ao lado dos jesuítas. Sob a responsabilidade dos beneditinos esteve a universidade de Salzburg na Áustria, fundada em 1623 uma das poucas exceções no ensino superior.

O ginásio de cunho católico nos Tempos Modernos abrangeu, em regra geral, cinco turmas, nas quais foram ensinadas as matérias do currículo: gramática, poesia, humanidades em geral, Latim e retórica. Cada turma tinha um professor e, após um exame no final do ano, os alunos passavam do ano. Os estudantes passavam por estudos propedêuticos a fim de aprender, suficientemente, a língua latina - base imprescindível de poder seguir as aulas.

A esses estudos preparatórios, anexou-se, na formação jesuítica, um tipo de ensino médio: o ensino da filosofia em três anos na faculdade artística. A faculdade artística recebeu, em média, três quartos (70$80 \%)$ dos alunos universitários nos Tempos Modernos. (HAMMERSTEIN, 2003, p. 96). Com base nos escritos 
de Aristóteles, os alunos aprenderam dialética, lógica, filosofia natural, metafísica e ética. 0 professor, que dava as aulas para o curso e preparava a turma para o exame final, era um jesuíta ou um candidato de teologia mais jovem. Exames eram realizados, obrigatoriamente, na matemática e na física, previstos também nas disciplinas secundárias.

O terceiro passo, segundo a Ratio studiorum, era o estudo da teologia de quatro anos. As matérias do curso da teologia eram - com base nos escrítos de Aristóteles e da Escolástica espanhola tardia - teologia, controvérsia, exegética, direito canônico e casuística. Candidatos de teologia estudavam, em regra geral, as disciplinas no ensino médio. Para os futuros sacerdotes comuns ou para os candidatos menos talentosos, havia um curso simplificado de teologia com duração de só dois anos. Esse curso seguia, diretamente, para o ginásio. "Métodos e matérias da instrução jesuítica se basearam numa teologia escolástica (tomista). Ao mesmo tempo, eles respiraram o espírito humanista (limitado), como era próprio aos regulamentos da escola e instrução protestantes" (HAMMERSTEIN, 2003, p. 39).

Entre os métodos didáticos e pedagógicos da Companhia de Jesus se destaca o teatro jesuítico, um instrumento de instrução religiosa e moral e de comunicação oral. Provindo de exercícios retóricos e exercícios de língua latina, os alunos começavam a representar cenas bíblicas, como a história de Natal, da Paixão e da Páscoa. No decorrer dos tempos, outros temas foram incluídos no repertório das peças teatrais dos jesuítas, entre eles temas litúrgicos e sobre os sete sacramentos - como marca visível de distinção entre as igrejas católica e protestante -, biografias de santos, bispos, príncipes e reis ou matérias da história eclesiástica e secular.

Todos os temas ensinados pelos jesuítas foram, naturalmente, incluídos na visão cristã da história como desenvolvimento consequente e linear da história cristã da Criação do mundo por Deus, passando pelo nascimento de Jesus Cristo até o Juízo Final no fim do mundo - história dividida numa sequência de quatro impérios: o dos babilônicos, persas, gregos e romanos, forma de periodizar a história ainda em vigor nos Tempos Modernos (SCHULZE, 2010). 0 Império Romano, transferido dos Romanos para os Francos, foi o último, em que se vivia e em que se esperava o fim do mundo.

Além dos cursos de filosofia e teologia, os professores jesuíticos se dedicaram, também, a outras disciplinas e ciências como a matemática, a astronomia ou a física e, ainda, a questões da arquitetura ou farmácia, fazendo pesquisas e publicando estudos. Alguns representantes da Companhia de Jesus se tornaram cientistas e eruditos reconhecidos no mundo intelectual e acadêmico.

Em média, frequentavam entre 200 e 500 alunos os ginásios; às vezes mais que 1000. No ginásio jesuítico de Munique, houve, no final do século XVI, 900 alunos e, em 1631, 1.500; em Würzburg houve, temporariamente, mais que 1.000 alunos e o colégio em Paris, um dos maiores e mais famosos da Companhia de Jesus no período, intitulado Louis le Grand, abrigou por volta de 1.700 alunos, chegando, às vezes, até a 3.000 alunos. Nos grandes colégios, havia, geralmente, mais de 70 padres, entre eles 15 professores, todos mantidos pelos soberanos dos respectivos territórios. Nos colégios pequenos, frequentemente ligados com um seminário como o Concílio de Trento havia recomendado, pelo menos, 30 padres.

As aulas, tanto nos ginásios e liceus como nas universidades, eram drigidas a todos os candidatos de talento sem qualquer restrição social, embora houvesse cursos especiais também para jovens nobres. A partir de 1550, as instituições escolares da Companhia estiveram acessíveis, também, para não-jesuítas, o que aumentou, enormemente, o número dos alunos. Foram recebidos também alunos protestantes. Os soberanos dos territórios católicos, os príncipes e bispos aceitaram a atuação dos jesuítas por razões práticas; eles adquiriram assim uma rede 
escolar da melhor qualidade e um corpo docente extremamente competente por um preço pequeno.

Para o ensino dos jesuítas, os pais não tiveram de pagar nada; as aulas nas instituições jesuíticas foram gratuitas. Por essas razões, a ordem conseguiu influenciar não somente a comunidade católica, mas também toda a sociedade contemporânea, sobretudo por meio das suas sodalidades e confrarias direcionadas a leigos que pretenderam uma vida segundo os princípios inacianos como, por exemplo, as Congregações Marianas.

A primeira congregação mariana foi fundada no ano de 1563 pelo flamengo João Leunis (1532-1584) em Roma, para promover a religiosidade, a ciência e a unidade de vida e fé (HAUB, 2007, p. 45). As primeiras congregações no Sacro Império, promovidas especialmente pelos jesuítas Franz Coster (1532-1618) e Jakob Rem (1546-1618), nasceram em Viena (1573), Dillingen (1574), Colônia (1576), Koblenz (1582) e Augsburg (1588). (KRAMMER, 1988, p. 168-195; KLUETING, 1989, p. 286). Essas congregações nascentes ao redor das escolas e universidades jesuíticas objetivaram, também, a melhorar os costumes dos alunos e os seus estudos. As congregações marianas se tornaram focos de uma religiosidade católica de modo típico para o barroco, caracterizada por procissões e romarias, missas e devoções, confissão e comunhão (HARTMANN, 2008, p. 72).

\section{UNIVERSIDADES COMO INSTITUIÇ̃̃O EUROPÉIA}

Universidades como instituições do ensino superior encontram-se hoje em todos os continentes, as suas origens, porém, remontam ao mundo medieval da Europa, onde nasceram no século XII. Elas podem ser consideradas, como o historiador alemão Peter Baumgart (1992, p. 71) afirma, “[...] uma instituição de ensino especificamente européia da Alta Idade Média e dos Tempos Modernos [...], a qual não pode ser derivada de uma instituição de ensino de nenhuma outra civilização desenvolvida”.
A nova cientificidade da Escolástica, por um lado, e as transformações sociais ocorridas no século XII, que se manifestaram em novas formas corporativas da sociedade, como as corporações, as guildas ou as ordens religiosas, por outro lado, resultaram na fundação das primeiras universidades na Europa - diferentes das instituições de ensino conhecidas até esse momento histórico (MÜLLER, 1996, p. 9).

Do ponto de vista da disseminação, o modelo da universidade europeia foi um grande sucesso, como somente os números provam: após os primórdios nos séculos XII e XIII, com as fundações em Bolonha, Paris e Oxford, havia, por volta de 1300, já cerca de 20 universidades na Europa e, cem anos mais tarde (1400), cerca de 30 universidades. Ao todo, foram fundadas entre 1200 e 1500 quase 80 universidades na Europa ${ }^{3}$. Entre 1500 e o fim dos Tempos Modernos (até 1790), o número subiu a 143 universidades stricto senso na Europa (MÜLLER, 1996, p. 55 e 65). Além disso, as universidades foram implantadas, no mesmo período, também na América do Norte, América Central e na América do Sul e começaram a conquistar todos os cantos do mundo. Hoje em dia, a instituição universitária está presente no mundo inteiro, sendo, depois da igreja católica, a instituição europeia mais antiga (KOCH, 2008).

As universidades se tornaram, no decorrer da Idade Média e dos Tempos Modernos, lugares de literatura (escrita) e cultura, de ciência e pesquisa e de discussão e reflexão. Com base nas tendências políticas e intelectuais contemporâneas, os professores e eruditos acadêmicos se dedicaram, nessas instituições de ensino superior, às questões fundamentais do homem, do mundo e do além, estabelecendo os fundamentos intelectuais, sempre mais racionais e seculares da Europa, e considerados gerais, absolutos e normativos e, consequentemente, os únicos possíveis e legítimos no mundo inteiro.

3. Cerca de 20 na Itália, na França e no Sacro Império Romano-Germânico, 8 na Espanha e em Portugal, 7 nas ilhas britânicas, 3 na Europa Oriental (Cracóvia, Pecs, Buda) e 2 na Escandinávia (Copenhague e Upsala) (MÜLLER, 1996, p. 12, 44; VERGER, 2002, p. 59). 
Esse padrão intelectual eurocêntrico se tornou a base intelectual e medida de todas as coisas na percepção, compreensão e avaliação do mundo desconhecido, do homem estranho e do outro fora da Europa nos Tempos Modernos e Contemporâneos e, às vezes, até no século XXI. Ao redor das universidsades se estabeleceu, especialmente a partir da época do Humanismo renascentista, por vários meios de comunicação como cartas, viagens e encontros, um público intelectual (europeu).

Apesar desta aparência uniforme das universidades em todos os continentes do mundo e em todas as épocas da história, a instituição da universidade passou por várias modificações e alterações no decorrer dos tempos. Enquanto as primeiras universidades provieram de uniões autônomas dos docentes e discípulos, das assim chamadas universitates magistrorum et scholarium, a instituição logo se encontrou numa relação estreita com as autoridades seculares e eclesiásticas.

Inicialmente os dois poderes universais, o Império e o Papado, outorgaram e garantiram os privilégios universitários, em seguida, foram os Estados pré-modernos que se haviam constituído a partir da Idade Média ou haviam se emancipado da dependência do Sacro Império, e as três igrejas confissionias - católica, luterana e calvinista - nascidas em confronto uma contra as outras ${ }^{4}$ a partir dos tempos da Reforma Protestante, da Renovação Católica e da Contra-Reforma, que aumentaram sempre mais a sua influência sobre as universidades. No período do assim chamado Confessionalismo nos séculoos XVI e XVII, as universidades eram fortemente fiscalizadas pelas respectivas igrejas nascentes, antes de o processo secularização acentuar-se nelas cada vez mais - processo típico de toda a Europa - e os Estados começarem a se apoderar, mais notadamente, dos recursos universitários.

4. O conceito historiográfico do Confessionalismo defende a tese de que as três igrejas nasceram e se institucionalizaram, paralelamente, a partir do século $\mathrm{XVI}$, cada uma delas se considerando como a religião original e pretendendo continuá-la e reconstituí-la; de fato, todas estas igrejas continham elementos velhos e novos (BURKHARDT, 2009, p. 32).
Em meados do século XVII, no fim da Guerra dos Trinta Anos (1648), havia, na parte católica do Império Sacro Romano-Germânico, ao todo, 18 universidades todas elas, com exceção da universidade beneditina de Salzburg (1622) (SCHINDLING, 1994, p. 3), sob a forte influência da Companhia de Jesus, especialmente nas faculdades de filosofia e teologia (HENGST, 1981, p. 53 e SCHINDLING, 1994, p. 3). Focalizaremos, em seguida, as universidades católicas de cunho jesuítico diante da história geral das universidades nos Tempos Modernos e do desenvolvimento histórico geral.

\section{UNIVERSIDADES COM FACULDADES JESUÍTI- CAS E UNIVERSIDADES JESUÍTICAS}

Nas universidades tradicionais com quatro faculdades (filosofia, direito, medicina e teologia), os jesuítas dominaram quase sempre as faculdades de teologia e, muitas vezes, as de filosofia, ocupando todas as cátedras. Na historiografia, fala-se de 'universidades com faculdades jesuíticas', como, por exemplo, no caso da Universidade de Coimbra, em Portugal. No Sacro Império Romano-Germânico, os jesuítas conseguiram, até o final da Guerra dos Trinta Anos (1618-1648), entrar e dominar a grande maioria das 18 universidades católicas existentes naquele momento histórico.

'Universidades com faculdades jesuíticas' foram, por exemplo, as Universidades de Colônia (fundada em 1388) com presença jesuítica desde 1556; de Tréveris (fundada em 1473), para onde os jesuítas foram chamados, em 1561, pelo Arcebispo de Freiburg e onde conseguiram dominar as faculdades de filosofia e teologia a partir de 1620; deWürzburg (fundada em 1582), onde o Príncipe-Bispo Julius Echter de Mespelbrunn (1545-1617, príncipe-bispo desde 1573) havia conseguido, em 1575, os privilégios universitários tanto do papa como do imperador ou de Innsbruck na Áustriam, fundada em 1669 (BAUMGART, 1992).

No caso de Münster, localizada em Vestfália, houve diferentes planos de transformar o ginásio jesuítico 
numa universidade. Embora tivesse, desde 1631, os privilégios universitários dos dois poderes universais, a Universidade de Münster foi inaugurada somente em 1780 (WEISS, 2005).

Os colégios jesuíticos, ligados geralmente com instituições escolares do ensino superior, foram completados, muitas vezes, por seminários, institutos para a formação dos futuros teólogos, instituições (Alumnat) para a educação dos jovens nobres e por internatos (Konvikt) para abrigar e educar alunos até o seu ingresso na universidade (SCHUBERT, 1970, 87). O complexo de um colégio jesuítico nem sempre foi estruturado de modo claro, transparente e fácil de compreender, consistindo, frequentemente, de diferentes institutos escolares ligados, direta ou indiretamente, a ele.

Quando um colégio se tornava núcleo de uma universidade, a estrutura era ainda mais confusa e complicada. Assim o historiador alemão Ernst Schubert (1970, p. 88) explicou, “[...] é difícil compreender a estrutura confusada universidade contrarreformista sob o suporte dos jesuítas, o que, frequentemente, dificulta também o entrelaçamento espacial e a compreensão pelos professores - pessoal dos singulares institutos”. Essa situação complicada se tornou ainda mais confusa, pois "[...] A universidade contrarreformista não foi criação, por via de doação (fundação), só de um Estado, mesmo sendo fictícia, mas é uma universidade de fundações acumuladas" (SCHUBERT, 1970, p. 88).

Enquanto as universidades funcionaram até 0 início dos Tempos Modernos, na maioria dos casos, em prédios alugados ou conventos secularizados, nos tempos da Reforma Protestante e da Contrarreforma, ou seja, da 'Confessionalização', foram construídas, também, nos territórios do Sacro Império Romano-Germânico as primeiras instalações físicas, exclusivamente dedicadas ao ensino superior. Orientados nos modelos da Universidade de La Sapienza em Roma e do Archiginásio em Bolonha, que foi o prédio principal da universidade dali e datou de meados do século XVI, foram construídos os edifícios universitários centrais de Altdorf, localizado perto de Nürnberg, entre 1571 e 1583, de Würzburg entre 1582 e 1591 e de Helmstedt entre 1592 e 1612.

A atuação da Companhia de Jesus na direção da universidade e dos seus diferentes institutos anexados, introduzindo um novo princípio no ensino superior, “[...] a unidade da educação e do ensino” (SCHUBERT, 1970, p. 89), resultou, finalmente, numa certa uniformização da organização geral e tradicionalmente confusa. A influência crescente da Companhia de Jesus sobre as universidades católicas confundiu os limites entre as duas entidades. Quanto mais o colégio jesuítico e a universidade eram entrelaçados, tanto mais as hierarquias da ordem e da universidade se confundiam. No caso das assim chamadas 'universidades jesuíticas', as hierarquias foram quase idênticas.

A Companhia de Jesus fundou e administrou algumas universidades por própria conta, as assim chamadas 'universidades jesuíticas' (Jesuitenuniversitäten), consistindo somente de duas faculdades: a Faculdade de Filosofia e a Faculdade de Teologia - sendo, portanto, 'semi-universidades', ou seja, universidades não completas ou universidades em parte. Essas 'universidades jesuíticas' foram dominadas, exclusivamente, por jesuítas e subordinadas, diretamente, à Companhia de Jesus. O superior do colégio jesuítico foi, ao mesmo tempo, o superior da universidade e das suas instituições (seminários, internatos, convictos etc.). Os professores universitários numa 'universidade jesuítica' - todos eles sendo membros da Companhia de Jesus - foram subordinados ao reitor do colégio, ao provincial da ordem e ao general da ordem em Roma, e retirados da própria jurisdição universitária privilegiada.

Dessa forma, a autonomia original das universidades diminuiu enormemente ou até desapareceu completamente. A hierarquia universitária e a hierarquia da ordem foram idênticas, assim o professor deveu, de certa forma, uma dupla obediência. A Faculdade artística foi frequentemente ligada a um ginásio jesuítico, o qual assumiu mais e mais a formação pro- 
pedêutica dos futuros estudantes em detrimento das próprias faculdades artísticas, que foram afastadas mais e mais da conexão com a universidade.

Esse novo tipo de universidade foi caracterizado pelos seguintes sinais: um soberano territorial (eclesiástico) foi fundador e mecenas, porém, ele não ocupou nenhuma função oficial na universidade. A universidade foi confiada, completamente, à Companhia de Jesus e ficou, consequentemente, retirada da influência do soberano. A administração da universidade, a nomeação de professores e a jurisdição acadêmica coube, exclusivamente, à Companhia de Jesus (HENGST, 1981, 163-294, sobretudo 163). As relações estreitas entre os colégios dos jesuítas se refletiram, também, na rede das 'universidades jesuíticas'.

Estatutos de uma universidade foram adotados por outra. Especialmente as transferências de professores, sobretudo da faculdade artística, de uma universidade para outra resultaram no estabelecimento de redes de universidades e colégios que colaboraram, estreitamente e em conjunto. Manifestaram-se, por exemplo, certas carreiras acadêmicas, seguindo a um esquema de transferências de uma para outra universidade. Muitas vezes, os membros do corpo docente foram docentes e alunos ao mesmo tempo.

\section{A COMPANHIA DE JESUS E O ESCLARECIMENTO}

As universidades católicas - sejam as 'universidades jesuíticas' como em Dillingen, sejam as 'universidades com faculdades hesuíticas' como em Ingolstadt ou Würzburg - fundadas ou reorganizadas na época da Reforma e Contrarreforma - representaram um típo específico de universidades e foram nomeadas pelos contemporâneos de "academias católicas". Os membros dessas universidades foram obrigados, ao ingressar na instituição, a fazer um juramento à fé católica e tridentina. A universidade de Dillingen, como primeira universidade jesuítica na Alemanha, exigiu, a partir de 1565, a profissão de fé tridentina (professio fideitridentinae). foram anexadas a essas universidades católicas contrarreformistas, que estiveram sob a forte influência dos jesuítas, tipografias privilegiadas. Essas tipografias, assim como os professores, foram também subordinadas à jurisdição dos jesuítas. As publicações ali impressas serviram não só ao ensino, mas também à missão, à propaganda e à polêmica contra os protestantes na vizinhança.

Ao lado das instituições escolares e do ensino superior, direcionadas à educação, os colégios dos jesuítas se tornaram centros da assistência religiosa e da missão. Os padres visitaram as paróquias nas respectivas cidades e no campo, pregando, proferindo o verbo de Deus e persuadindo aqueles que simpatizavam com o protestantismo. Desse modo, o príncipe-bispo de Würzburg, Julius Echter, conseguiu transformar o seu território majoritariamente protestante no início do seu episcopado (1573), num território quase que exclusivamente católico no fim do seu episcopadao (1617).

Enquanto a Ratio studiorum foi, no século XVII, atual, moderna e inovadora, os conteúdos do currículo e os métodos didáticos e pedagógicos dos jesuítas se tornaram, no decorrer do século XVIII, sempre mais ultrapassados e antiquados. A Ratio studiorum ficou quase 200 anos inalterada e deixou de ser desenvolvida, não se adaptando às novas exigências de um mundo em transformação. No século XVIII, o currículo jesuítico já não deu mais as respostas certas aos novos problemas. No sistema fixo e monolítico dos jesuítas faltou, levada ao extremo, qualquer liberdade, criatividade e força inovadora. 0 ensino superior da Companhia de Jesus serviu sobretudo à conservação do saber conhecido e dos conhecimentos adquiridos, mas não à pesquisa e inovação.

As publicações - em nossos dias um dos itens fundamentais para avaliar a qualidade de professores e universidades - de autoria jesuítica foi pequena em relação ao seu número: de 212 professores jesuíticos que atuaram entre 1553 e 1773 na Universidade jesuítica de Dillingen, somente 144 publicaram textos, 
constata Hammerstein (2003, p. 42), e dos 94 professores da Universidade de Ingolstadt somente 20. Com o progresso e fortalecimento das idéias iluministas a partir do fim do século XVII, quando a teologia perdeu o seu poder e espaço no discurso público e intelectual, os jesuítas "perderam a conexão com o desenvolvimento intelectual do tempo" (HAMMERSTEIN, 2003, p. 42).

Nos tempos do 'Confessionalismo', o Curso de Direito e o pensamento jurídico possibilitaram - acima das confissões disputantes - ao público erudito o desenvolvimento de métodos inovadores e de uma erudição dinámica, porém os jesuítas ignoraram, em grande parte, essa área de conhecimento, perdendo assim uma chance de renovação (HAMMERSTEIN, 2003, p. 42 e 92). Vale a pena lembrar que muitos representantes do iluminismo da sua primeira fase foram juristas como Christian Thomasius (1655-1728) ou Christian Wolff (1679-1754), os dois atuando na Universidade prussiana de Halle.

A gênese de princípios modernizantes e inovadores contribuiu na transição do mundo medieval para o mundo moderno e iniciou um processo de transformação que fez-se notar sempre mais evidente e fortemente. No século XVIII, essa dinâmica de mudança resultou, finalmente, no pensamento esclarecido, que aumentou a velocidade e a profundidade das transformações do mundo, o qual se tornou sempre mais secularizado.

Em meados do século XVIII, quando a Societas Jesu foi abolida, primeiramente em 1759 em Portugal, depois em 1767 na Espanha e, em geral, em 1773, a Companhia de Jesus se tornou o alvo preferido das críticas dos iluministas e foi considerada a representante típica da superstição, escuridão e medievalidade distante. Os fundamentos antigos foram abalados, intelectualmente, pelo iluminismo e, politicamente, pela Revolução Francesa. As colunas do Antigo Regime foram destruídas - entre elas a Societas Jesu, que havia perdido as suas forças inovadoras em um mundo transformado e se tornou, sempre mais, a representação exemplar de inimigo do progresso e do esclarecimento. A influência dos jesuítas sobre as universidades católicas havia chegado, definitivamente, ao seu fim.

\section{REFERÊNCIAS}

BURKHARDT, Johannes. Deutsche Geschichte in der frühen Neuzeit. München: Verlag C. H. Beck, 2009.

FRIEDRICH, Markus. Der lange Arm Roms? Globale Verwaltung und Kommunikation im Jesuitenorden (1540-1773). Frankfurt/ New York: Campus Verlag, 2011.

HAMMERSTEIN, Norbert. Bildung und Wissenschaft vom 15bis zum 17 Jahhundert (= Enzyklopädie deutscher Geschichte. Bd. 64). München: R. Oldenbourg Verlag, 2003.

HARTMANN, Peter C. Die Jesuiten. München: Verlag C. H. Beck, 2008.

HAUB, Rita. Die Geschichte der Jesuiten. Darmstadt: Wissenschaftliche Buchgesellschaft, 2007.

\section{HENGST, Karl. Jesuiten an Universitäten und}

Jesuitenuniversitäten. Zur Geschichte der Universitäten in der Oberdeutschen und Rheinischen Provinz der Gesellschaft Jesu im Zeitalter der konfessionellen Auseinandersetzungen (= Quellen und Forschungen aus dem Gebiet der Geschichte. Neue Folge. Bd. 2), Paderborn et al.: Verlag F. Schöningh, 1981.

\section{KAUSCH, Winfried. Geschichte der Theologischen}

Fakultät Ingolstadt im 15. Und 16. Jahrhundert (1472-1608 (= Ludovico Maximilianea. Forschungen und Quellen. Bd. 9). Berlin: Duncker \& Humblot, 1977.

\section{KRAMMER, Otto. Bildungswesen und}

Gegenreformation. Die Hoghen Schulen der Jesuiten im katholischen Teil Deutschlands vom 16. bis zum 18. Jahrhundert (= Veröffentlichungen des Archivvereins 
der Markomannia. Nr. 31), Würzburg: Gesellschaft für deutsche Studentengeschichte 1988.

\section{KRAUS, Andreas. Das Gymnasium der Jesuiten} zu München (1559-1773). Staatsgeschichtliche, sozialgeschichtliche, behördengeschichtliche und kulturgeschichtliche Bedeutung (= Schriftenreihe der Bayerischen Landesgeschichte. Bd. 133), München: Verlag C. H. Beck, 2001.

\section{MEIER, Johannes. "Totus mundus nostra} sit habitatio". Jesuiten aus dem deutschen Sprachraum in Portugiesisch - und Spanisch Amerika (= Akademie der Wissenschaften und der Literatur. Abhandlungen der Geistes - und sozialwissenschaftlichen Klasse. Jg. 2007, Nr. 2), Mainz: Akademie der Wissenschaften und Literatur(Stuttgart: Franz Steiner Verlag 2007.

\section{MÜLLER, Rainer A. Geschichte der Universität.}

Von der mittelalterlichen Universität zur deutschen Hochschule, Hamburg: Nikol Verlag, 1996 (original München: Verlag Georg D. W. Callwey 1990).

MÜLLER, Winfrtied. Universität und Orden. Die bayerische Landesuniversität Ingolstadt zwischen der Aufhebung des Jesuitenordens und der Säkularisation 1773-1803 (= Ludovico Maximilianea. Forschungen und Quellen. Bd. 11), Berlin: Duncker \& Humblot, 1986.

\section{SCHINDLING, Anton. Bildung und Wissenschaft} in der Frühen Neuzeit 1650-1800: Enzyklopädie deutscher Geschichte. Bd. 30), München: R. Oldenbourg Verlag, 1994.

\section{SCHUBERT, Ernst. Zur Typologie gegenreformatorischer Universitätsgründungen:} Jesuiten in Fulda, Würzburg, Ingolstadt und Dillingen. In:Rössler, Hellmuth/Franz, Günther (Org.). Universität und Gelehrtenstand 1400-1800 (= Deutsche Führungsschichten in der Neuzeit, v.4), Limburg/Lahn: C. A. Starke Verlag, 1970. p.85-105.

\section{SCHULZE, Winfried. Einfürhung in die Neuere}

Geschichte, 2010.

\section{WEISS, Dieter J. Katholische Reform und}

Gegenreformation. Ein Überblick, Darmstadt: Wissenschaftliche Buchgesellschaft, 2005. 